\title{
A Probe into the Differences Between China English Rhythm and
}

\section{American English Rhythm}

\author{
ZHANG Hong-zhen, YI Li, KANG Shi-hui \\ China Agricultural University, Beijing, China
}

\begin{abstract}
This thesis makes a comparative study on the differences between China English rhythm and American English rhythm as well as the relationship between speakers' intonation perception and production with the combined method of sound recording and perception test. Chinese is Tone Language, while English is Intonation Language. Although both tone and intonation are manifested by pitch variation, tone is used to convey the meaning at the word level, while intonation at the sentence or discourse level. The findings of the research indicate that while learning a foreign language based on intonation, Chinese English speakers, as influenced by their tone language, have great difficulties in grasping the rhythm pattern. This is also confirmed by the perception test. The research suggests that we should pay more attention to the training of intonation rather than the pronunciation of single words.

Keywords: China English, pitch, intonation, rhythm
\end{abstract}

\section{Introduction}

Intonation is the soul of a language (Kindon, 1958). Mastering the intonation of a language is like mastering its soul, while mastering the vocabulary and grammar is just mastering its basic structure. To our Chinese English learners, the most difficult part of learning English lies in that our mother tongue (Chinese) is Tone Language, while our target language (English) is Intonation Language. Despite the fact that both tone and intonation are manifested by pitch variation, tone is used to distinguish words, while intonation is used to distinguish whole sentences (Ladefoged, 2009). More often than not, Chinese English learners will put great emphasis on the correctness of the segmental pronunciation. While for suprasegmental parts, their intonation is usually influenced by their tonetic characteristics. As a result, although they can pronounce a single word correctly, it is still far from enough to grasp the intonation of the whole sentences.

The hypothesis of this thesis is that Chinese English learners' intonation is influenced by their tonetic characteristics. Based on this, the thesis aims to probe into the deviation degree of the rhythm pattern between China English and American English as well as Chinese English speakers' perception of intonation. The subjects are proficient speakers who have used English as their working language for a long time. Their rhythm patterns will be analyzed and the reason for the deviation will also be discussed. Finally, a perception test is conducted to confirm the conclusion.

ZHANG Hong-zhen, postgraduate student at College of Humanities and Development Studies, China Agricultural University. YI Li, associate professor at College of Humanities and Development Studies, China Agricultural University.

KANG Shi-hui, postgraduate student at College of Humanities and Development Studies, China Agricultural University. 


\section{Empirical study}

\section{Research Hypothesis and Question}

The research hypothesis is that Chinese English speakers' speech defects lie in that Chinese is Tone Language while English is Intonation Language. Based on this, this thesis makes a comparative study on the rhythm pattern between China English and Standard English, the former of which is based on practical recordings of Chinese native speakers who have used English for a long time. Also, a perception test is conducted as an additional part of the research. The research questions are as follows: (1) Q1: What is the deviation degree of rhythm pattern between China English and American English and the possible underlying reason?; and (2) Q2: What is the relationship between Chinese English speakers' intonation perception and production?.

\section{Research Subjects}

The research subjects are 10 Chinese English speakers who have studied and used English for many years. The majority of the speakers major or majored in English, four are undergraduates, three are postgraduates, and one is a senior interpreter. Although the last two are not English majors, they have studied and lived in America for many years. We can say that their English proficiency is decent. At least to those "China English" users, their pronunciation is "standard" and acceptable. Here a quotation mark is added to emphasize that the so-called "standard" is only aimed at the "China English" users. The last requirement for the speakers is that they all identify their pronunciation as American English and admit that American English is their learning goal and the most imitated spoken language.

\section{The Selection of Cardinal Pronunciation}

The reason that this thesis chooses American English, instead of British English as cardinal pronunciation lies in that, at present, the majority of English learners in China choose American English. This has largely to do with the economic position of America and its global strategy.

Given the fact that American English has many regional pronunciation differences, it is impossible to sort out so-called "standard American English". So this research selects a published teaching material named American Accent Training as its cardinal pronunciation. The book is to help foreigners to "sound American", and the sound in it is spoken and understood by the majority of educated native speakers, it is spoken in the way a professor gives lectures to a class, the way a national newscaster broadcasts, and the way that is most comfortable and familiar to the majority of native speakers (Cook, 2000). Apart from this, the authors also record a middle-aged American woman's speech as auxiliary reference.

\section{Research Methods and Reading Materials}

A lot of research has been done to study the speech's focus and boundary tone and elaborative studies have studied on the Chinese English speakers' rhythm characteristics according to different sentence forms like statements and interrogatives. For example, apart from speech's focus, XU (1999) considered word stress and part of speech as the influencing factor on rhythm. His research pointed out that the F0 curve of statements and interrogative began to show their difference from the occurrence of the first stressed content word. WANG, YANG, and LV (2004), based on large corpus with both low and fast speed, made an investigation on the acoustic correlates to prosodic hierarchical boundaries in Chinese. XIONG (2003) analyzed the boundary features of different levels of prosodic units in continuous speech based on read corpus. 
This research minimizes the study parameter, and only discusses the general rhythm pattern rather than the specific boundary tone or the speech focus. It discusses the most common rhythm pattern-the pattern of narrative speech. As with the study on grammar, which takes narrative speech as its default language state, the study on rhythm can also start from the narrative speech. Therefore, the material selected is a narrative story from American Accent Training titled three little pigs (see Appendix), and the rhythm pattern of the whole story is a typical three-word-phrase story. Actually, two-word, four-word, and five-word phrases are also included in this book. However, in this study, the material used are three-word phrases, hoping it will be more representative. There are 217 words in the material, of which the three-word phrases amount to 34 . However, in later analysis, the authors omit two relatively simpler phrases, and add one four-word phrase and one five-word phrase, in order to differentiate the difficulties.

The rhythm parameter the thesis uses is pith. During the process of analyzing, the authors cut out the three-word phrases and divided them into 34 intonation groups. Then the authors extract the pitch of Chinese English speakers', Native American speakers', and the speaker from American Accent Training, and calculate the mean value and draw the intonation curve. For the data of Chinese English speakers, some are from individuals, and the others are from the mean value of all the speakers.

Among the 11 participants, 10 are Chinese English speakers, and one is a Native American whose data is used as auxiliary reference. There are all together 30 pitch points being extracted in each phrase. The Excel software is used to generate the curve graph, and analysis is made based on this curve.

\section{Results}

Table 1 shows the deviation and accordance of the rhythm curves between the Chinese English speakers and the speaker from American Accent Training. Considering that there are many data involved, the authors divide the table into three parts. Thirty-four sets of phrases are analyzed, but the first phrase is omitted, for the analysis of the first phrase involves all the speakers' data, which is used for individual analysis, and will be exemplified in another paper. So only the 2nd to the 34th are analyzed to find out whether the Native speaker and the Chinese English speakers' pitch curves match with that of cardinal pronunciation. The authors use the mark "+" to present textbook speaker's rhythm curve, then if the Native speaker and the Chinese English speakers' rhythm curves match with hers, it will be marked as “+”, if not, it will be marked as "-”. From Table 1, we can see that there are 13 times that the Native speaker's pitch curves matching with that of textbook speaker's. While for Chinese English speakers, there are only nine instances of matching, with match rate of only $27 \%$, which means that the Chinese English speakers' rhythm pattern is "nonstandard" under most circumstances.

Table 1

The Deviation and Consistency Among Speakers' Pitch Curves From Three Different Groups

\begin{tabular}{cccccccccccccccccccc}
\hline & 2 & 3 & 4 & 5 & 6 & 7 & 8 & 9 & 10 & 11 & 12 & 13 & 14 & 15 & 16 & 17 \\
\hline $\mathrm{A}$ & + & + & + & + & + & + & + & + & + & + & + & + & + & + & + & + \\
$\mathrm{N}$ & + & + & + & + & + & + & - & + & + & + & + & + & - & - & - & - \\
$\mathrm{C}$ & - & - & + & + & - & - & - & + & - & - & - & + & + & - & - & - \\
\hline 18 & 19 & 20 & 21 & 22 & 23 & 24 & 25 & 26 & 27 & 28 & 29 & 30 & 31 & 32 & 33 & 34 & + \\
+ & + & + & + & + & + & + & + & + & + & + & + & + & + & + & + & + & + \\
+ & + & - & + & - & + & - & + & - & - & - & + & + & + & - & - & + \\
+ & - & - & - & - & - & + & + & - & - & - & - & - & - & - & - & + \\
\hline
\end{tabular}


To further investigate the rules of deviation and accordance between the Chinese English speaker and textbook speaker, the authors divided the 31 sets of three-word phrases into different groups according to their components. Then the authors counted the number of each group and the corresponding numbers of which the Chinese English speaker's pitch curve are in accordance with that of the textbook speaker's. Given that there are many data involved, the table is also divided into two parts (see Table 2).

Table 2

The Components of Different Groups and the Corresponding Number of Accordance

\begin{tabular}{|c|c|c|c|c|c|c|c|c|c|}
\hline $\begin{array}{l}\text { Components } \\
\text { of phrase }\end{array}$ & $\begin{array}{l}\text { Num. + Adj. } \\
+ \text { n. }\end{array}$ & $\begin{array}{l}\text { Adj. + Adj. } \\
+ \text { n. }\end{array}$ & $\begin{array}{l}\text { Pro. + Adj. } \\
+ \text { n. }\end{array}$ & $\begin{array}{l}\text { Adj. + n. } \\
+ \text { n. }\end{array}$ & $\begin{array}{l}\text { Adv. +Adj. } \\
+\mathrm{n} .\end{array}$ & $\begin{array}{l}\text { V. + Pron. } \\
+ \text { Adv. }\end{array}$ & $\begin{array}{l}\text { Adv. + Adv. } \\
+ \text { Adj. }\end{array}$ & $\begin{array}{l}\text { Adj. + Adj. } \\
+ \text { n. }\end{array}$ & $\begin{array}{l}\text { Compound } \\
+\mathrm{n} .\end{array}$ \\
\hline $\begin{array}{l}\text { Numbers of } \\
\text { occupation }\end{array}$ & 7 & 9 & 1 & 3 & 1 & 3 & 1 & 1 & 5 \\
\hline $\begin{array}{l}\text { Numbers of } \\
\text { accordance }\end{array}$ & 2 & 0 & 1 & 0 & 1 & 1 & 0 & 1 & 2 \\
\hline
\end{tabular}

From Table 2, we can see that phrases that are made up of Adjective + Adjective + Noun (9 groups) have the largest number of occupation (30\%) in the whole passage, followings are the Quantifier + Adjective + Noun (7 groups), Adjective + Noun + Noun and Verb + Pronoun + Adverb (3 groups), the remaining ones only appear once. Among them, the rhythm curves of "their own houses" (Pronoun + Adjective + Noun), "very, hard worker" (Adverb + Adjective + Noun) and "large, dark forest" (Adjective + Adjective + Noun) between the Chinese English speaker and the textbook speaker match with each other. Just as both speakers' rhythm curves of the phrase "large, dark forest" shown in Figures 1-2, both speakers' rhythm curves have two peaks, and the intonation curve in general is very similar. The reason of this similarity lies in that the stress in the three groups is relatively easy to locate, and once the stress is pronounced correctly, the general intonation curve is mastered. Turning to the phrase that is made up of "Adjective + Adjective + Noun", which has the largest number of occupation, we can see that all the rhythm curves of the Chinese English speakers fail to match with that of the textbook speakers'. Take the pitch curves of the phrase "kind old mother" for example, as shown in Figures 3-4, we can see that there are two peaks in the textbook speaker's rhythm curve, while the average Chinese speakers' curve shows a smooth trend without any obvious fluctuation. This inconsistency lies in that it is hard to locate the stress when there are two modifying components of the same part of speech, thus the rhythm curve will deviate from that of the standard. Similarly, the phrases made up of "Adjective + Noun + Noun" and "Adverb + Adverb + Adjective" show the same trend. Therefore, we try to draw the conclusion that it is hard for the Chinese English speaker to locate the stress and grasp the rhythm curve when two components are of the same part of speech in the three-word phrase. As for the remaining three sets of phrases, the rhythm curves of both groups of speakers alternate between consistency and inconsistency, and so no rules can be found.

In order to investigate the relationship between Chinese English speakers' intonation perception and production, the authors conduct an intonation perception test as an additional research. Two Native Americans are invited to listen to the recordings of the 10 China English speakers', and then marks are given from the intonation aspect. Finally, three speakers' recordings are chosen whose marks are among the highest three. Their recordings, together with that of the textbook speaker's, compose the material for this perception test. There are 33 phrases involved (except the first one), and the remaining seven speakers participate in the perception test, 
they are asked to choose the recording of the textbook speaker's from the four kinds of recordings. The results show that although all of the test-takers can distinguish the Native speaker's recording correctly, they cannot explain the reasoning for their judgments, nor can they tell the differences between the Native speaker and China English speakers' intonation patterns. This indicates that although China English speakers can sense different intonations; they cannot grasp the rules of the rhythm pattern.

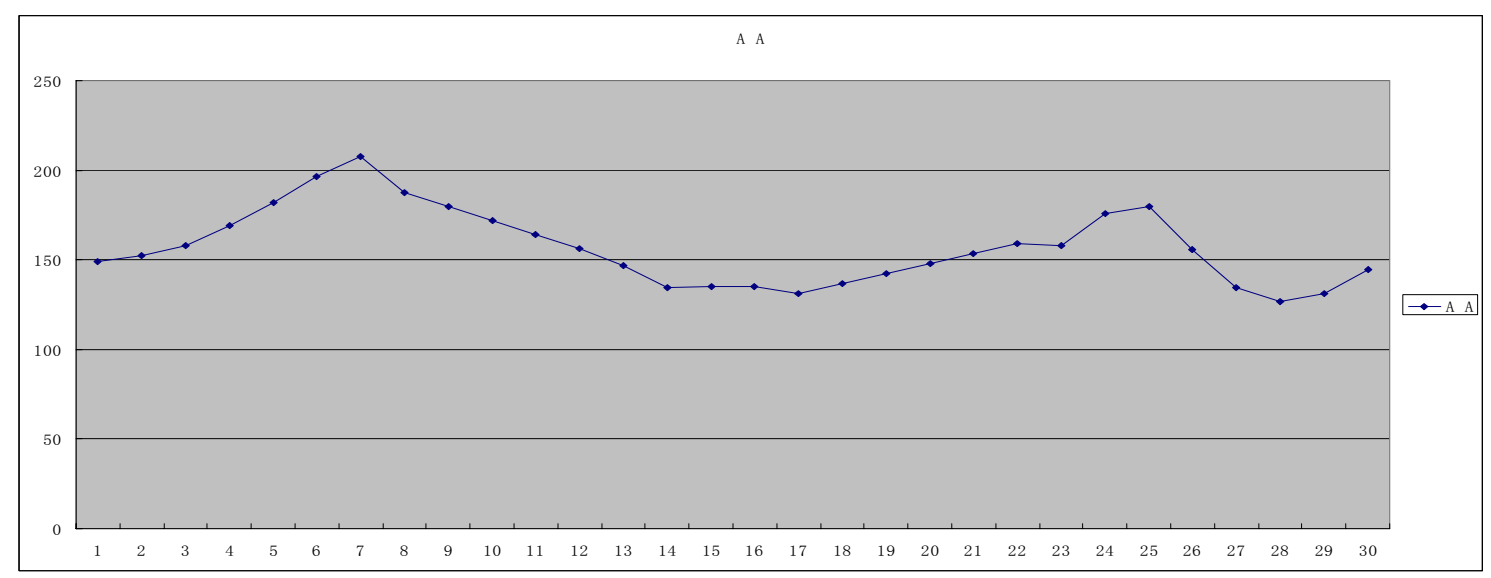

Figure 1. Pitch curve of "large, dark forest" from the textbook speaker.

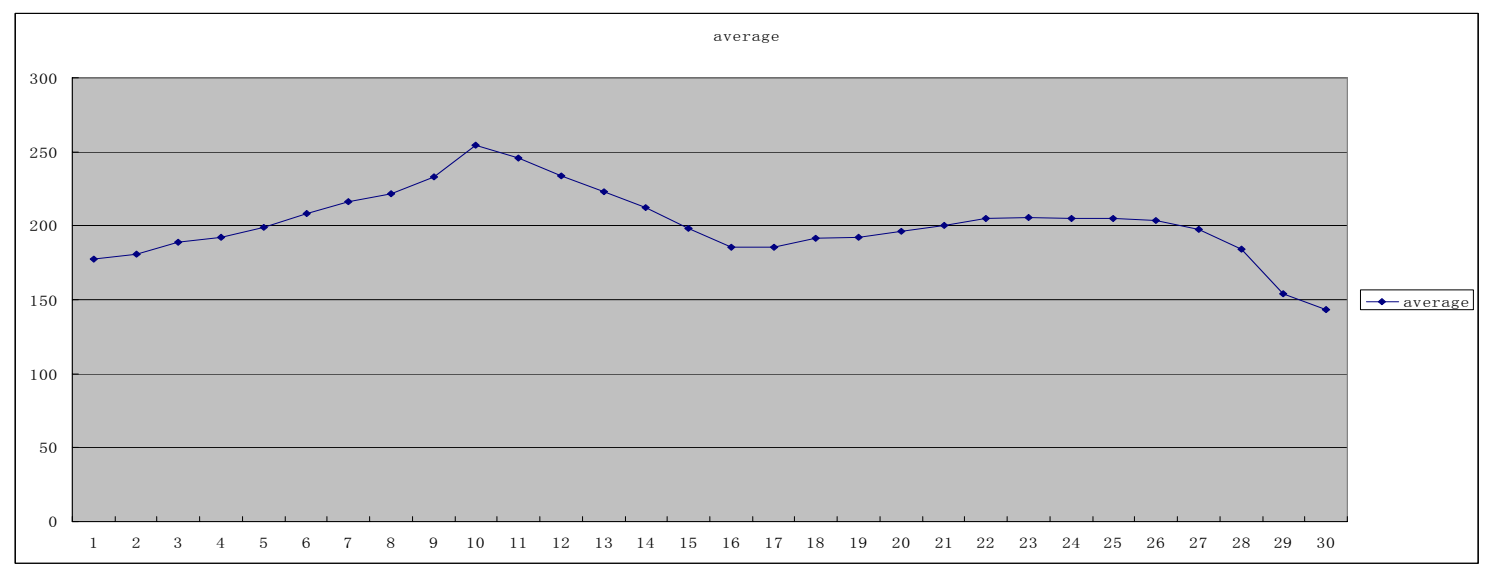

Figure 2. Pitch curve of "large, dark forest" from the average Chinese English speaker.

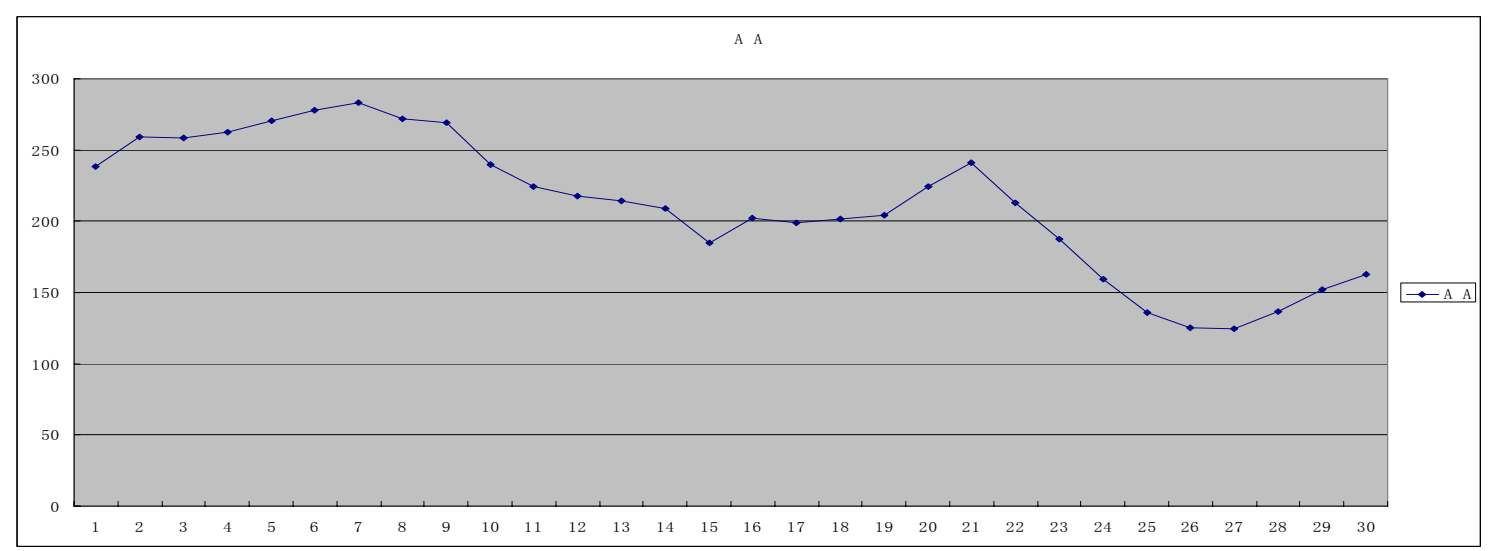

Figure 3. Pitch curve of "kind old mother" from the textbook speaker. 


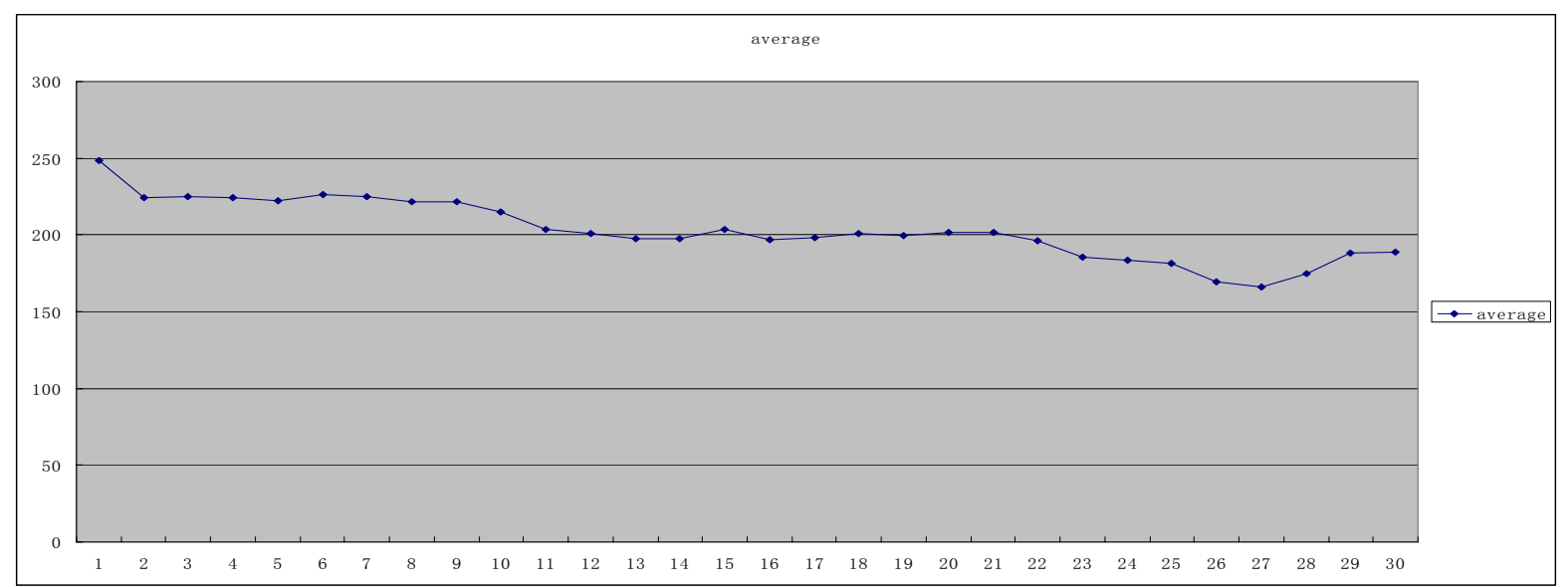

Figure 4. Pitch curve of "kind old mother" from the Chinese English speaker.

\section{Conclusions}

According to the research, the rhythm curves drawn on the basis of extracted pitch which are in accordance with those of the native speakers' are less than one third. The intonation perception test also indicates that although China English speakers can distinguish different intonations, they cannot tell the reason and criteria for their judgment, for they cannot grasp the rules of the rhythm pattern.

For most of the time, our pronunciation by reading single words could not be the criteria for our general pronunciation; but rather, the rhythm, to some extent, can reveal whether our English pronunciation is "native" or not. This research also provides some insight for English teaching that we should pay more attention to the training of intonation rather than only to the pronunciation of single words.

\section{References}

Alan, C. (2002). Intonation. Beijing: Peking University Press.

Cook, A. (2000). American accent training (2nd ed.). Hauppague: Barron's English Series.

Gibbon, D., \& Richter, H. (1984). Intonation, accent and rhythm: Studies in discourse phonology. Berlin: New York: de Gruyter. GUO, J., \& SHI, F. (2011). Experimental study of declarative and interrogative intonation in English and Chinese. Contemporary Foreign Languages Studies, (1), 5-11.

GUO, J., \& XIAO, Q. D. (2010). An analysis of the declarative intonation in English. Nankai Linguistics, (4), 57-69.

Kindon, R. (1958). The groundwork of English intonation. London: Longman, Green and Co, LTD..

Ladefoged, P. (1996). Elements of acoustic phonetics (2nd ed.). Chicago: The University of Chicago Press.

Ladefoged, P. (2003). Phonetic data analysis: An introduction to instrumental phonetic fieldwork. Oxford: Blackwells.

Ladefoged, P. (2009). A course in phonetics (5th ed.). Beijing: Foreign Language Teaching and Research Press.

LIN, M. C. (2006). Interrogative vs. declarative and the boundary tone in standard Chinese. China Language, (4), 364-376.

WANG, B., YANG, Y. F., \& LV, S. N. (2004). Acoustic analysis on prosodic hierarchical boundaries of Chinese. ACTA ACUSTIICA, 29(1), 29-36.

XIONG, Z. Y. (2003). An acoustic study of the boundary features of prosodic unit. Applied Linguistics, (2), 117-121.

XU, Y. (1999). Effects of tone and focus on the formation and alignment of F0 contours. Journal of Phonetics, (27), 55-105.

YANG, Y. F. (1997). Prosodic cues to syntactic boundaries. ACTA ACUSTIICA, (5), 414-421.

YUAN, Y. (2008). A corpus-based longitudinal study on prosodic prominence of discourse markers in English majors' read speech. Journal of PLA University of Foreign Languages, 31(1), 43-47. 


\section{Appendix: Three-Word Phrase Story}

(1)Once upon a time, there were (2)three little pigs. They lived with their (3)kind old mother near a (4)large, dark forest. One day, they decided to build (5)their own houses. The first little pig used straw. He took his (6)straw-cutting tools and (7)his new lawn-mower, and built a (8)little straw house. The second little pig used sticks. He took his (9)wood-cutting tools and some (10)old paintbrushes and built a (11)small wooden house. The (12)third little pig, who was a (13)very hard worker, used bricks. He took his (14)brick-laying tools, an (15)expensive mortar-board, and built a (16)large brick house. In the forest, lived a (17)big bad wolf. He wanted to eat the (18)three little pigs, so he went to the (19)flimsy straw abode and tried to (20)blow it down. "Not by the hair of my chinny chin chin!” cried the (21)three little porkers. But the house was (22)not very strong, and the (23)big bad beast (24)blew it down. The (25)three little pigs ran to the (26)rickety wooden structure, but the (27)big bad wolf (28)blew it down, too. Quickly, the (29)three little piggies ran to the (30)sturdy brick dwelling and hid inside. The (31)big bad wolf (32)huffed and he puffed, but he couldn't blow the strong brick house down. The (33)three little pigs (34)laughed and danced and sang. 